\title{
Clinical models to compare the safety and efficacy of inhaled corticosteroids in patients with asthma
}

\author{
Krishnan Parameswaran MBBS MD MNAMS MRCP(UK) FCCP1, \\ Richard Leigh MBChB MSC FCP(SA) ${ }^{1}$, Paul M O'Byrne MBChB FRCPI FRCPC FCCP ${ }^{1}$, \\ Margaret M Kelly MBChB FCPath(SA) ${ }^{1}$, Charlie H Goldsmith PhD², \\ Frederick E Hargreave MBChB MD FRCP FRCPC ${ }^{1}$, Myrna Dolovich PEng ${ }^{1}$
}

K Parameswaran, R Leigh, PM O’Byrne, MM Kelly, $\mathrm{CH}$ Goldsmith, FE Hargreave, M Dolovich. Clinical models to compare the safety and efficacy of inhaled corticosteroids in patients with asthma. Can Respir J 2003;10(1):27-34.

There is no consensus on the methods to compare the clinical efficacy of different inhaled corticosteroids. A comparison needs to be made in terms of relative potency, and studies should include two-, or preferably, three-dose comparisons. A number of clinical models and outcomes are available; they have their relative advantages and disadvantages. While measurements of symptoms and spirometry are easy and readily available, they show a flat dose-response relationship. Measurements of bronchial hyper-responsiveness to exercise and adenosine monophosphate, allergen-induced airway responses, and measurements of inflammation in sputum and exhaled air show steep dose-response relationships, particularly to low doses of inhaled steroids. An uncontrolled asthma model followed by stabilization with a short course of additional steroid, with measurements of airway responsiveness and airway inflammation, in a crossover study seems more promising than the other models. Drug deposition studies and mathematical modelling of drug pharmacokinetics in the airway may provide complementary information to clinical drug relative potency studies. Fine particle dose and emitted doses, rather than the nominal dose, should be considered in the estimation of clinical and systemic effects, respectively. When a second entry (generic) drug is being evaluated in comparison with the innovator drug (same compound and same device), it may be appropriate to consider accepting a generic as bioequivalent if it satisfies pharmaceutical equivalence.

Key Words: Asthma; Clinical models; Efficacy; Inhaled corticosteroids; Outcomes; Relative potency; Safety

\section{Modèles cliniques visant à comparer l'effica- cité et l'innocuité des corticostéroïdes en aérosol chez des asthmatiques}

Le choix des méthodes permettant de comparer l'efficacité clinique de différents corticostéroïdes en aérosol ne fait pas consensus. Les études doivent avoir pour objet la puissance relative des médicaments et elles devraient comparer deux, voire trois, posologies. Il existe un certain nombre de modèles cliniques et d'analyse des résultats, chacun comportant ses avantages et ses inconvénients. Certes, les mesures de l'intensité des symptômes et la spirométrie se prennent facilement et rapidement, mais la relation dose-effet atteint un plateau. Par contre, les mesures de l'hyperréactivité des bronches à l'effort et à l'adénosine monophosphate ainsi que celles des réactions des voies aériennes aux allergènes et de l'inflammation dans les expectorations et l'air expiré montrent une forte relation dose-effet, en particulier aux corticostéroïdes en aérosol à faibles doses. Un modèle d'asthme non équilibré, suivi d'une période de stabilisation obtenue par une corticothérapie complémentaire de courte durée, comportant des mesures de la réactivité des voies aériennes et du degré d'inflammation, dans le cadre d'une étude avec permutation, semble plus prometteur que les autres modèles. Les études fournies pour les dépôts de médicament et la modélisation mathématique de la pharmacocinétique des médicaments dans les voies aériennes peuvent compléter les études sur la puissance relative des médicaments utilisés en clinique. Il faudrait tenir compte de la dose administrée sous forme de particules fines et de la dose distribuée, plutôt de que la dose nominale, pour l'évaluation des effets cliniques et généraux, respectivement. Lorsqu'un médicament générique est comparé au médicament d'origine (même composé, même dispositif), il peut être approprié de considérer le générique comme bioéquivalent si le médicament répond aux critères d'équivalence pharmaceutique.
$\mathrm{I}^{\mathrm{n}}$ nhaled corticosteroids (ICS)s are the most effective antiinflammatory drugs in the management of patients with asthma (1). Since the introduction of beclomethasone to the market in the mid-1970s, a number of new formulations, propellants and inhaler devices have been developed. It has been a constant challenge to clinicians, pharmacologists, government agencies and the pharmaceutical industry to develop methods to compare the clinical efficacy and safety of these different products (2). Whereas pharmacological equivalence can be evaluated using pharmacokinetic bioassays and in vitro drug deposition studies (3), the introduction of successful clinical models to determine relative potency has been problematic (4). The present report, based on a workshop organized by the Therapeutics Products Programme of Health Canada, summarizes the pros and cons of some of the clinical models used to compare different types of ICS preparations and different devices for their delivery. The report is not a review of comparative studies between various ICS preparations.

This report is based on the proceedings of an International Workshop on Inhaled Corticosteroid Relative Potency, May 11, 2000, Toronto, Ontario. The workshop was sponsored by the Therapeutics Products Programme, Health Canada

${ }^{1}$ Asthma Research Group, Firestone Institute for Respiratory Health, St Joseph's Healthcare, and Departments of Medicine; ${ }^{2}$ Clinical Epidemiology Eु Biostatistics, McMaster University, Hamilton, Ontario

Correspondence and reprints: Professor M Dolovich, Department of Medicine, Faculty of Health Sciences, HSC-1V18, McMaster University Medical Centre, 1200 Main Street West, Hamilton, Ontario L8N 325. Telephone 905-521-2100 ext 73454, fax 905-546-1125, e-mailmdolovic@mcmaster.ca 


\section{GENERAL PRINCIPLES OF COMPARATIVE STUDIES}

The therapeutic effects of inhaled drugs, and in particular corticosteroids, are influenced by a number of factors, such as the potency and pharmacodynamic properties of the drug, the aerosol properties of the drug, the amount of drug reaching the airways, the rate of systemic absorption, the type of inhaler device used and the severity of the disease. Safety assessments need to include systemic and local adverse effects, and a therapeutic ratio of the clinical efficacy and safety measurements should be considered. These issues have been discussed in detail elsewhere (4). Comparison of different preparations can be expressed in terms of bioequivalence or relative potency (Figure 1). Bioequivalence is the comparison of the same outcome measurement at a single dose each of at least two drugs being compared, whereas relative potency is the comparison of the same outcome measurement at two or more different doses of two or more drugs. Therefore, a clinically meaningful interpretation of comparative studies requires information on the relative potency.

\section{DESIGN AND STATISTICAL ISSUES}

Good design principles of any clinical trial must hold true for comparative studies of the relative potency of ICSs. Studies should have a prespecified sample size, balanced valid design with random allocation to treatment arms and blind assessment of clinically relevant outcome measures $(5,6)$. Although parallel study designs avoid carryover effects, a two-drug, twoperiod crossover design with a sufficient washout period is the most practical method of comparing two drugs, particularly in terms of manageable sample sizes. The crossover design also allows comparison in the same subjects. However, the design may not be able to detect crossover or interaction effects. This may be overcome by allowing an extra treatment washout period with an assumption that the carryover effect is constant in all research participants. The ideal washout period is not known. The general consensus is that it should be at least two to three weeks. Sample size calculation is based on the same principles of any crossover study, often with a type I error probability of 0.05 , type II error probability of 0.1 , and a predefined

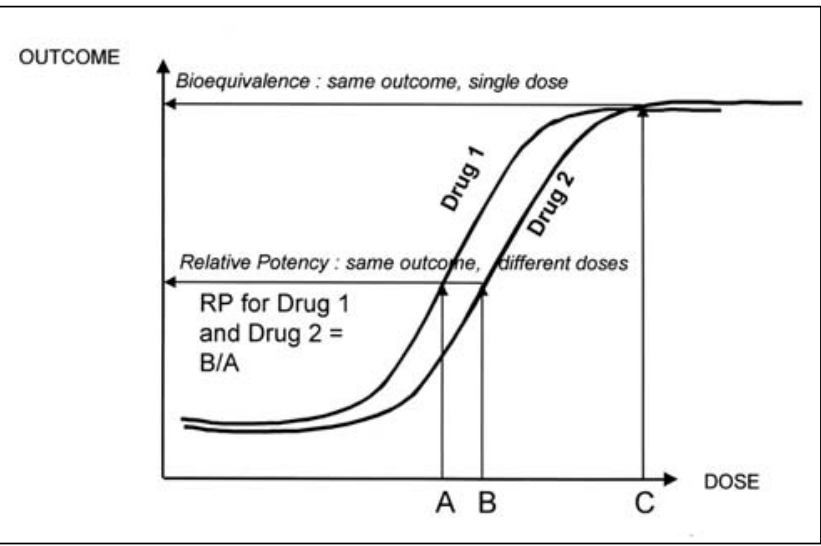

Figure 1) Relative potency and bioequivalence of for two drugs. A, B and $\mathrm{C}$ represent three different doses of the two drugs; RP Relative potency estimate of minimum clinically important difference in the outcome measure and its standard deviation (7). It varies depending on the outcome studied, study design, test statistic and tails of the test.

Additional consideration needs to be given to the doses that are selected for comparison and estimation of relative potency. Although it is generally believed that increasing doses of ICSs provide better clinical benefit, a clear dose-related response in clinical benefits have not generally been demonstrated in well-conducted clinical studies, with most of the clinical and anti-inflammatory effects being achieved at low doses of ICSs (8-11). Consequently, it is important to choose lower doses of different corticosteroids preparations for comparisons to ensure that the steep portions of the dose-response slopes are compared. At least three doses per drug should be chosen. Logically, a straight line model is the simplest and easiest model to test for parallelism, and to estimate the relative potency and its confidence limits using Finney's bioassay and Fieller's theorem (12). This generally uses a logarithmic or some transformed dose scale.

\section{CLINICAL MODELS AND OUTCOMES}

ICSs improve a number of clinical outcomes in asthma (1). They control airway inflammation, in particular eosinophilic inflammation, improve airway calibre and airway hyper-responsiveness, protect the airway against bronchoconstrictor stimuli such as exercise and allergens, and prevent asthma exacerbations, thereby improving symptoms and quality of life. The effects of different ICS formulations on any one of these outcomes or a combination of these outcomes can be compared to estimate relative potency. The choice of the outcome measurement depends on the ease and repeatability of the measurement, the doseresponse effect and the duration of treatment required to demonstrate the clinical effect.

An important factor is that the relative potency of two drugs may be different for different outcomes compared, depending on the dose-response relationship. For example, symptoms are nonspecific. Respiratory function tests such as forced expiratory volume in $1 \mathrm{~s}\left(\mathrm{FEV}_{1}\right)$ or peak expiratory flow (PEF) are sensitive only when their results are low to begin with and asthma is uncontrolled. When the results are normal or near normal, as is often the case in subjects chosen for relative potency studies, there is less room for improvement. This makes a comparison between formulations difficult, thus requiring very large, often impractical sample sizes. By contrast, measurements of inflammation, such as the level of nitric oxide in exhaled air and the proportion of eosinophils in sputum, appear to be more sensitive to change, particularly when the doses of ICSs are reduced $(2,9,10)$. Other factors, such as patient population (degree of lack of control, chronicity of disease, children versus adults), concomitant medications, previous treatment with corticosteroids and the properties of the inhaler device, can also influence the different outcome measurements to different extents $(2,13)$.

The following section focuses on some of the clinical models that have been developed and tested to compare the relative potency of ICSs. There is no 'best' or 'ideal' model or design, with each of the designs offering advantages and disad- 
TABLE 1

Clinical models and outcomes in comparative studies of inhaled corticosteroids

\begin{tabular}{|c|c|c|}
\hline Models & Outcomes & Comments \\
\hline Controlled asthma & Symptoms & Symptoms and spirometry are easy to perform, shallow dose-response, \\
\hline Allergen provocation & Spirometry: $\mathrm{FEV}_{1}$, PEF & $\begin{array}{l}\text { large sample size provocation models need special expertise, } \\
\text { studies can run for long duration }\end{array}$ \\
\hline Exercise/methacholine/AMP & AHR & \\
\hline Uncontrolled asthma & Inflammation: blood, sputum, exhaled air & Measurement of inflammation not widely available \\
\hline Natural & Measurement of adverse effects & Recruitment for clinical studies may be difficult with natural exacerbations \\
\hline Steroid reduction & eg, cortisol, osteocalcin & Easier to recruit, more difficult to conduct the studies, needs rigorous follow-up \\
\hline
\end{tabular}

AHR Airway hyper-responsiveness; AMP Adenosine monophosphate; FEV forced expiratory volume in 1 s; PEF Peak expiratory flow

vantages. The different outcomes listed above can be examined in each of these models (Table 1). Broadly, the outcomes can be studied when the asthma is controlled (controlled asthma model) or uncontrolled (uncontrolled asthma model). The usual outcome in a controlled asthma model is airway responsiveness (or measurements of inflammation) to an inhaled allergen, exercise or other stimuli such as methacholine or adenosine monophosphate (AMP). Asthma may be uncontrolled either naturally (natural exacerbation model) or by reducing the dose of corticosteroids directly or by halving the maintenance dose of the ICS when the trial drugs are added to therapy (steroid reduction models) (14). Single dose comparisons where the trial drug is given in two or more doses to a small group of patients and a single dose of another drug that has previously demonstrated dose-response is given to the larger group of patients (15), equal dose comparisons (16) and two doses to single dose comparisons (17) provide information on efficacy, but do not allow estimation of relative potency and are, therefore, not considered in this discussion.

\section{Controlled asthma model}

When asthma is well controlled, commonly measured outcomes such as symptoms, $\mathrm{FEV}_{1}$ and inflammatory markers may be almost normal (18). Therefore, it may not be possible to demonstrate a dose-response effect with increasing doses of ICS. The outcome measure that is still be abnormal, with a potential for further improvement, is airway hyper-responsiveness (AHR). Because airway responsiveness is determined in part by the baseline $\mathrm{FEV}_{1}$ (19), it can be reliably assessed only when the $\mathrm{FEV}_{1}$ is near to normal, ie, when asthma is controlled.

Airway response to allergen inhalation: Allergen inhalation by a subject with atopic asthma results in an early asthmatic response (EAR) and, in nearly $50 \%$ of subjects, is followed by a late asthmatic response (LAR). A single dose of an ICS administered before allergen inhalation or during the EAR has no effect on the EAR, whereas it attenuates the LAR (20-22). When used regularly for one week or more before allergen inhalation, ICSs significantly attenuate EAR and almost completely abrogate the LAR (23). Previous studies that evaluated the effects of either single doses $(200$ and $800 \mu \mathrm{g}$ of budesonide and an investigational drug) of ICSs on LAR (24) or regular daily doses (200, 400 and $800 \mu \mathrm{g}$ of budesonide each for seven days) of ICS on the EAR (25) did not show a dose-response relationship, which was discouraging for this model to be used for estimation of relative potency. The maximum attenuating effect of airway responses were observed with the lowest dose studied. In a subsequent randomized, placebo controlled, crossover study, Inman et al (26) compared the effects of 100,200 and $800 \mu \mathrm{g}$ daily doses of mometasone furoate for six days on allergen-induced airway responses in 12 patients with mild asthma. The three doses of mometasone caused a dose-dependent attenuation on the magnitude of the LAR (from 23.5\% maximum fall in $\mathrm{FEV}_{1}$ with placebo treatment to $12 \%, 11 \%$ and $6 \%$ respectively), while dose-dependent suppression of sputum eosinophilia was observed only with the 100 and $800 \mu \mathrm{g}$ doses at $24 \mathrm{~h}$ after the allergen inhalation. This suggests that at lower doses of ICSs, the allergen challenge model can be useful in comparing different ICSs. However, this requires expertise and careful attention to the method of allergen challenge and involves a number of allergen challenges.

Airway responsiveness to direct and indirect stimuli: AHR to direct and indirect stimuli is a characteristic feature of patients with asthma. Treatment with ICS attenuates the bronchoconstrictor responses to both direct stimuli such as methacholine and indirect stimuli such as exercise and AMP.

Although long term treatment with ICSs improves methacholine AHR significantly, in some cases even into the normal range (27), a dose-response relationship has not been demonstrated (25).

Pedersen et al (11) demonstrated a significant dose-dependent attenuation of exercise-induced bronchoconstriction in a randomized, placebo controlled, crossover study in 19 children. Daily doses of 100, 200 and $400 \mu \mathrm{g}$ of budesonide for four weeks caused a $53 \%, 70 \%$ and $83 \%$ protection, respectively, in exercise-induced drop in $\mathrm{FEV}_{1}$. This suggests that this bronchial provocation test may be used to compare ICSs.

Bronchial provocation with the mast cell stimulating agent AMP is believed to be a more sensitive indicator of airway inflammation than the other direct and indirect challenges in patients with asthma (28). Taylor et al (28) studied the effects of three doses of the novel corticosteroid ciclesonide $(50,200$, and $800 \mu \mathrm{g}$ ) inhaled as a dry powder twice daily on airway responsiveness to AMP. In a three parallel dose group, doubleblind, placebo controlled, randomized, crossover study, with a 


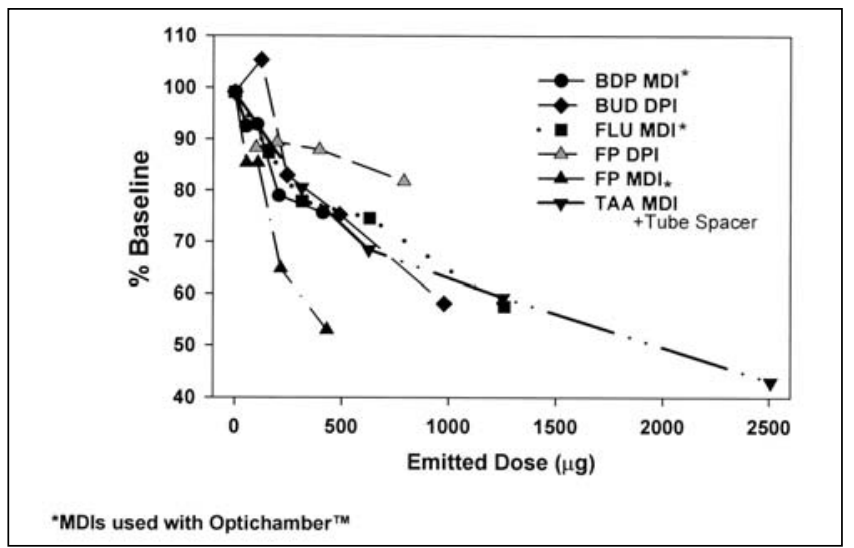

Figure 2) Area under the curve for cortisol versus emitted doses from six inhalers. *Used with Optichamber (Healthscan [Respironics], USA) tube spacer; BDP Beclomethasone dipropionate; BUD Budesonide; DPI Dry powder inhaler; FLU Flunisolide; FP Fluticasone dipropionate; MDI Metered dose inhalers; TAA Triamcinolone acetonide. Data replotted from reference 34, courtesy author M Dolovich

washout period of three to eight weeks, a total of 29 subjects with asthma underwent AMP challenge before and after 14 days of treatment with ciclesonide or a matched placebo. Compared with the placebo, 100, 400 and $1600 \mu \mathrm{g}$ of ciclesonide daily reduced airway responsiveness to AMP by 1.6, 2.0, and 3.4 doubling doses, respectively. This reduction in airway responsiveness was dose-dependent. However, a further study of the effects of a single dose and three doses of 100, 250 and $1000 \mu \mathrm{g}$ daily of fluticasone or a matching placebo in 12 patients with mild asthma caused attenuation of AMP hyperresponsiveness, which was not dose-dependent (29). This suggests that the duration of treatment, in addition to the dose of ICSs, is an important determinant of the success for this model for comparison between ICSs.

For either model, it is important to consider the safety of different ICS preparations when their clinical efficacy or potency is being compared. The most important measurements of safety include the effects on the bone and the hypothalamic-pituitary-adrenal (HPA) axis (30). Few studies have attempted to examine efficacy and side effects concurrently and to establish a therapeutic ratio $(31,32)$. One of the problems with such studies has been the choice of measurements used to assess the systemic activity of ICSs. For example, a single measurement of morning cortisol is an imprecise indicator of HPA axis suppression, whereas measurements of $24 \mathrm{~h}$ and overnight urine cortisol, with concurrent assessment of creatinine clearance, and measurement of cortisol levels after a stimulation test are more sensitive (33). It is important to consider these issues in calculating the therapeutic ratio.

The National Heart, Lung and Blood Institute Asthma Clinical Research Network (NIH/ACRN) has conducted a series of studies, with the above issues in mind, to characterize the beneficial and systemic effects of various inhaled steroiddelivery device combinations. Six inhaled steroids were evaluated for a dose response analysis on cortisol suppression (34). The systemic efficacy of the inhaled steroids was compared at doses (both nominal dose, ie, label claim, and emitted or inhaled dose) selected for specific levels of cortisol suppression (Figure 2). For example, there is very little difference in the doses of different formulations in causing a 10\% suppression in serum cortisol (which may be of doubtful clinical significance). Fluticasone as a dry powder inhaler does not cause any greater than $10 \%$ cortisol suppression, suggesting that it has perhaps the lowest systemic effect. However, if the doses are compared at greater degrees of cortisol suppression, the differences in systemic activity become more obvious. For example, fluticasone delivered through a metered dose inhaler causes a 60\% suppression of cortisol at a lower dose than does budesonide delivered as a dry powder (Figure 2). This information may be useful to characterize the relative beneficial effect of selected steroids at levels of equisystemic effect based on cortisol suppression. The information also emphasizes the importance of considering the nature of the delivery devices when interpreting clinical studies reporting contrasting systemic efficacies of different ICSs $(32,35)$.

\section{Uncontrolled asthma model}

Naturally uncontrolled: In this design, subjects with mildly symptomatic asthma are randomly assigned to receive two or more doses of two or more different formulations or devices, in a crossover, or in a parallel study. The major limitation of this method is the inability to demonstrate a significant doseresponse effect of ICSs on the usual clinical outcomes of symptoms and spirometry. However, if patients with moderately or severely uncontrolled asthma are enrolled in the study, this may not be a problem. A recent rigorous, randomized, placebo controlled parallel study in 323 patients with asthma, comparing 100, 400 and $800 \mu \mathrm{g}$ doses of a hydrofluoroalkane (HFA) and chlorofluorocarbon formulations of beclomethasone, demonstrated a dose response for $\mathrm{FEV}_{1}$ and a relative potency of 2.6 for the HFA formulation compared with the chlorofluorocarbon formulation (8). The advantage of this model is that the clinical methods are simple and widely available. The difficulties are due to the requirement of large sample sizes because of the shallow slope of the dose-response as well as the parallel study design, and ensuring adequate patient compliance during the course of the study.

A second natural exacerbation model evaluates different ICSs based on their abilities to prevent asthma exacerbation. Patients with mildly uncontrolled asthma are stabilized by giving them a 'burst' of high dose of prednisone (36). After making a number of baseline measurements, including symptoms scores, spirometry and airway responsiveness, the patients are then randomly assigned to different doses, devices or formulations of ICSs until they have an exacerbation. Control is then re-established with a course of prednisone, and the patients crossover to the other treatment arm. The stability of patients on each treatment arm following the course of prednisone is compared. This method appears to provide the statistical power to estimate the relative potency of different inhaled corticosteroid formulations within an acceptable confidence interval for most of the outcomes studies, including morning and evening PEF, $\mathrm{FEV}_{1}$, symptom score and airway responsiveness, with a sample size of less than 100 subjects. The disadvantages of the model are the need for high doses of prednisone, and the variable and unpredictable length of the 
washout period between the crossover arms. This may be overcome by using high doses of ICSs instead of prednisone.

ICSs may also be compared with respect to their effects on outcomes related to asthma pathology. Eosinophilic airway inflammation is a characteristic feature of asthma, and eosinophilic bronchitis is steroid responsive (37). A dosedependent attenuation of sputum eosinophilia by 100, 400 and $1600 \mu \mathrm{g}$ of budesonide has been reported by combining the results from two separate experiments (9). In a single-blind study, Kelly and colleagues (38) examined the effect of 50, 100, 200 and $400 \mu \mathrm{g}$ of fluticasone and a matching placebo daily for seven days in sequential order on 14 patients with mild asthma who had significant sputum eosinophilia at entry into the study (thereby making them uncontrolled). Measurements of spirometry, airway responsiveness, blood and sputum eosinophils, and exhaled air nitric oxide were made before each dose increment. All of the variables, except $\mathrm{FEV}_{1}$, demonstrated a doseresponse relationship. Sputum eosinophils and exhaled nitric oxide were responsive to low doses of fluticasone with plateau effects above $100 \mu \mathrm{g}$ daily. The provocative concentration causing a 20\% drop in $\mathrm{FEV}_{1}\left(\mathrm{PC}_{20}\right)$ of methacholine improved to $0.5,0.6,1.1$ and $1.5 \mathrm{mg} / \mathrm{mL}$ respectively, from a baseline of $0.3 \mathrm{mg} / \mathrm{mL}$ (a doubling dose shift in $\mathrm{PC}_{20}$ methacholine of 0.55 for each $100 \mu \mathrm{g}$ dose of fluticasone). The dose effects were confounded by the time effect in this cumulative design. However, the results are encouraging for using daily doses of 25, 50 and $100 \mu \mathrm{g}$ fluticasone compared with appropriate doses of another drug or delivery system. The advantage of this outcome is the relative ease and noninvasive nature of assessing doseresponse on the inflammatory components of asthma. As discussed above, the disadvantages are that techniques are not widely available and the confounding by the 'time effect' in a cumulative study design. On the other hand, a parallel study requires larger sample sizes and may not be practical.

Uncontrolled by steroid reduction: Most international guidelines recommend that to prevent overtreatment with ICSs, the lowest dose to maintain asthma control needs to be identified (39). This principle forms the basis of steroid reduction models. In a randomized, double-blind, parallel group study, Agertoft and Pedersen (40) allocated a large group of children who were well controlled on 400 to $800 \mu \mathrm{g}$ of ICSs to one-half the dose of either budesonide or fluticasone. At intervals of five weeks, the dose was further reduced by $50 \%$ until asthma was uncontrolled by a predefined criterion. The minimal effective doses of the two medications were then compared and found to be equally effective. In an unpublished study (S Pedersen, personal communication), the effect of the duration of steroid reduction phase was investigated. Patients with asthma who were controlled on $400 \mu \mathrm{g}$ of budesonide had their dose reduced by $50 \%$ either at two weekly, four weekly, eight weekly or 12 weekly intervals, until the dose was replaced by placebo. The proportion of patients who were able to replace the ICS with placebo were $46 \%, 23 \%, 10 \%$ and $8 \%$, respectively, for each of the reduction periods. It may be possible to compare these proportions using two different ICS formulations. In another model (S Pedersen, personal communication), patients with asthma who were controlled on $400 \mu \mathrm{g}$ of budesonide were randomly assigned to maintain their current dose for 12 weeks or half the dose $(200 \mu \mathrm{g})$ for 12 weeks. An exercise provocation test was per- formed at baseline and every four weeks. The magnitude of exercise-induced bronchoconstriction did not differ between the two groups after four weeks of treatment, but was significantly greater for the group on the lower dose of ICS at eight weeks and 12 weeks of treatment compared with the group on the original dose. This model may also be useful in comparing different ICS formulations.

These studies suggest the following: prestudy patient characterization and dose titration intervals are important considerations; standard definitions should be used to define terms such as 'optimal control', 'acceptable control', 'unacceptable control' and 'exacerbation' during the study; and an exercise test can be combined with a steroid reduction model. These models have studied 50\% dose-reductions and not lower. It is expected to be able to detect differences in outcome measures even if the doses are reduced by $30 \%$ at each step. The problems with studies of long duration are interference with natural exacerbations due to allergen exposure or respiratory tract infections.

\section{Mathematical models}

The purpose of using inhaled steroids in preference to systemic steroids is to maximize pulmonary targeting and to minimize systemic exposure. Both local and systemic exposure can also be assessed by pharmacokinetic measures (41). Direct measurements of active drug concentrations in the lung by microdialysis or ex vivo receptor binding assays are only possible in animal studies. Planar scintigraphy (twodimensional) and single photon emission computed tomography (SPECT) (three-dimensional) used to assess topical dose and regional lung distribution have the disadvantage of measuring only the radiolabel, which requires manipulation of the investigated product. Direct labelling of the drugs is not possible with these two imaging techniques. The indirect labelling methods used are more of a concern when testing ICS formulated as suspension aerosols, but can be an alternative for those formulated as solutions or powders, particularly if the latter are labelled with a nonabsorbable compound (42). Necessary requirements of radiolabelled deposition studies are the demonstration of comparability between the aerosol properties for the manufacturer's drug and the labelled drug, the latter in terms of both radioactivity and drug, and imaging immediately following inhalation due to the rapid absorption of the radiotracer (43).

Pharmacokinetics can be employed to characterize the absorption profile from the lung after blocking gastrointestinal absorption using activated charcoal. However, this does not mimic a 'real life' clinical situation. Systemic exposure is best assessed by the direct measurement of the drug and active metabolite concentrations in plasma. This is possible today due to vastly improved analytical chromatographic techniques. It is possible for two ICSs to have a similar plasma concentration profile to meet the criteria for bioequivalence with different absorption profiles. Pharmacokinetic bioequivalence can complement the in vivo clinical studies of comparison of ICSs (44).

\section{Lessons from drug deposition studies}

Therapeutic aerosols are heterodisperse, containing particles or droplets of varying sizes. The emitted dose of a drug 


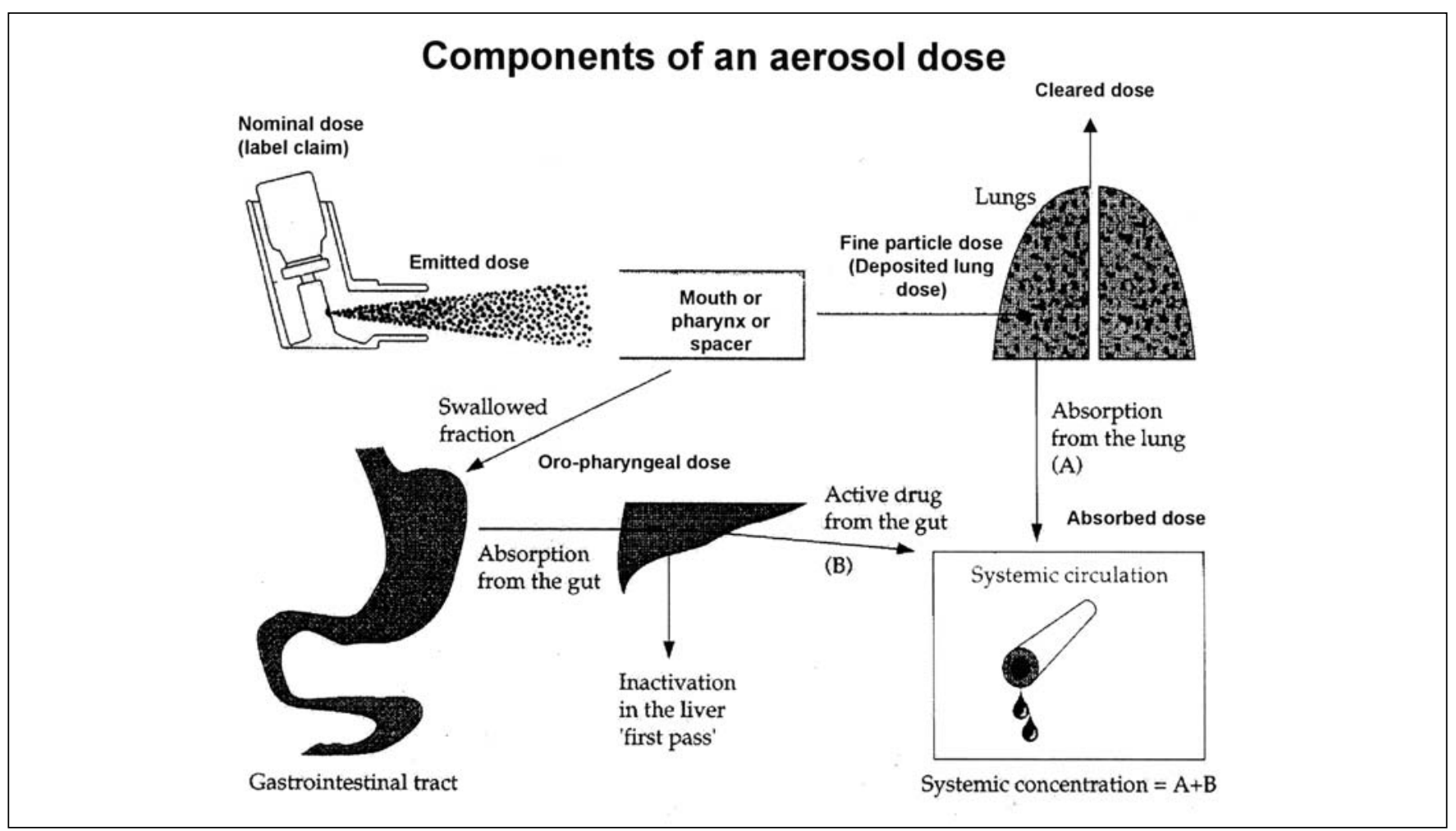

Figure 3) Components of an aerosol dose. Adapted with permission from reference 50

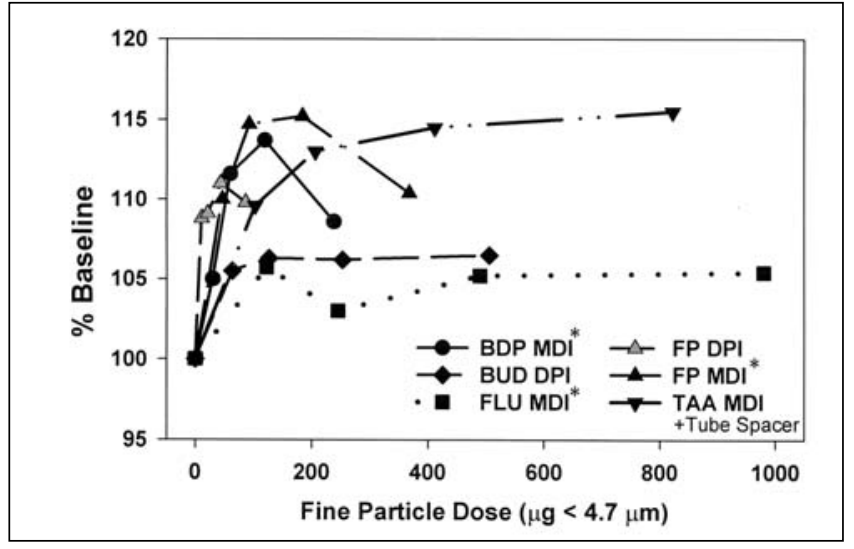

Figure 4) Morning forced expiratory volume in $1 \mathrm{~s}$ versus fine particle dose from six inhalers. *Used with Optichamber (Healthscan [Respironics], USA) tube spacer; BDP Beclomethasone dipropionate; BUD Budesonide; DPI Dry powder inhaler; FLU Flunisolide; FP Fluticasone dipropionate; MDI Metered dose inhalers; TAA Triamcinolone acetonide. Data replotted from reference 34, courtesy author M Dolovich

from an inhaler can be differentiated, using in vitro techniques, into its coarse and fine particle fractions. Once inhaled, the site of deposition is be governed primarily by these size fractions. Coarse particles deposit in the oropharynx and the large central airways, and the fine and extrafine particles deposit mainly in the small, peripheral airways. Additionally, airway caliber and airflow dynamics during inhalation greatly influence deposition and distribution of a drug in the lung. Reduced calibre and high inspi- ratory flow shifts the site of deposition predominantly to the oropharynx and more proximal airways even for fine aerosols, increasing the surface concentration of drug in these areas. Clinical outcomes and side effects from an inhaled drug are determined by the surface dose at the site of deposition, as well as absorbed and retained drug in the lung and body. Therefore, measurement of the size characteristics of the aerosol from the particular inhaler being tested, quantification of the specific dose fractions within the aerosol and the measurement of in vivo deposition using radiolabelled drugs are key elements for a more accurate interpretation of dose-response relationships.

Traditionally, dose-response studies are based on the 'nominal dose' ('label claim') of the ICS that is administered. This dose is greater than the 'inhaled' or 'emitted' dose due to losses in the delivery device and is also greater than the 'fine particle dose', which is the portion of the emitted dose that is likely to deposit below the larynx (Figure 3). For pressurized metered dose inhalers used without a valved spacer device and for dry powder inhalers, a large portion of the emitted dose is retained in the oropharynx and swallowed ('oropharyngeal dose'), contributing to the systemic dose, albeit at a later time point (45). The fine particle dose is deposited in the lung ('deposited dose'), of which a portion is retained following mucociliary clearance ('retained dose') or absorbed from the lung ('absorbed dose'). The distribution of the emitted dose can be imaged using two dimensional (planar imaging) or three-dimensional techniques such as SPECT and positron emission tomography scans (46).

The dose-response curves and the clinical relevance vary depending on the test doses selected (47), or the patient pop- 
ulation tested (48). If the dose-response curves are plotted in terms of emitted dose (for systemic responses) (Figure 2 ) and fine particle dose (for pulmonary effects) (Figure 4), rather than the label claim, the outcomes can be viewed in terms of the doses causing the specific responses, as seen with the data from the NIH/ACRN comparison of six ICSs (34). This also allows one to view the drug or inhaler that gives rise to the least cortisol suppression while maintaining a reasonable clinical outcome in terms of $\mathrm{FEV}_{1}$.

In another example, it has been shown in patients with asthma that beclomethasone-HFA (QVAR, 3M Pharmaceuticals, USA) has approximately three times greater lung deposition (49), with about 2.5 to 3.2 times greater clinical efficacy and about 1.2 times the systemic effects (8) than beclomethasone-chlorofluorocarbon (Beclovent, GlaxoSmithKline, USA) for the same microgram dose administered. In other words, the same dose equivalency does not apply to the emitted doses as to the lung (fine particle) doses. Therefore, it may be necessary to measure the portion of the steroid aerosol that has a high probability of depositing in the peripheral lung, ie, the fine particle dose, and to compare the clinical outcomes at these doses. This is particularly relevant when testing the same drug administered from different devices (35) and is a consideration for future studies comparing different ICSs.

\section{SUMMARY OF RECOMMENDATIONS}

The comparison of ICS preparations needs to be made in terms of relative potency, and studies should include two or, preferably, three dose comparisons. When a second entry (generic) drug is being evaluated, compared with the innovator drug (same compound and same device), rather than constructing dose-response curves, it may be appropriate to consider accepting a generic as bioequivalent if it satisfies pharmaceutical equivalence. A number of clinical models and outcomes are available to estimate the relative potencies of ICS. They have their relative advantages and disadvantages. While measurements of symptoms and spirometry are easy and readily available, they show a flat doseresponse relationship. Measurements of bronchial hyperresponsiveness to exercise and AMP, allergen-induced airway responses, and measurements of inflammation in sputum and exhaled air show steep dose-response relationships, particularly to low doses of ICSs. However, these tests are more difficult to perform and are not readily available. An uncontrolled asthma model followed by stabilization with a short course of high dose steroid (inhaled or ingested) with measurements of airway responsiveness and airway inflammation in a crossover study seems to be more promising than the other models. Drug deposition studies and mathematical modelling of drug pharmacokinetics in the airway may provide complementary information to clinical drug relative potency studies. Such studies are specialized, expensive and require the support of both industry and government regulatory bodies. Finally, fine particle doses and emitted doses, rather than the nominal dose, should be considered in the estimation of clinical and systemic effects, respectively, because they relate specifically to the doses inhaled and deposited in the lung, and the estimation should also normalize differences between inhaler devices.

ACKNOWLEDGEMENTS: We thank K Read for organizing the symposium, Dr S Pedersen for reviewing the manuscript, and all the participants for their contributions. Dr K Parameswaran and Dr R Leigh are supported by postdoctoral fellowships from the Canadian Institutes of Health Research.

\begin{tabular}{|l|}
\hline APPENDIX \\
Participants: McMaster University, Hamilton, Ontario: M Dolovich \\
(Chair), FE Hargreave, PM O’Byrne, MD Inman, K Parameswaran, \\
CH Goldsmith, R Leigh, MM Kelly, L Jayaram; Therapeutic Products \\
Programme, Ottawa, Ontario: P Roufail, E Ormsby; University of Iowa, \\
Iowa City, Iowa: R Ahrens; Laval University, Sainte-Foy, Quebec: LP \\
Boulet; University of Florida, Gainesville, Florida: H Derendorf; Imperial \\
College, London, Englan: BJ O'Connor; University of Southern \\
Denmark, Kolding, Denamrk: S Pedersen; Food and Drugs \\
Administration, Rockville Maryland: E Sullivan; The National Jewish \\
Hospital, Denver, Colorado: S Szefler
\end{tabular}

\section{REFERENCES}

1. Barnes PJ. Inhaled corticosteroids for asthma. N Engl J Med 1995;332:868-75.

2. Pedersen S, O'Byrne P. A comparison of the efficacy and safety of inhaled corticosteroids in asthma. Allergy 1997;52(Suppl 39):1-34.

3. Chrystyn H. Methods to identify drug deposition in the lungs following inhalation. Br J Clin Pharmacol 2001;51:289-99.

4. Boulet LP, Cockcroft DW, Toogood J, Lacasse Y, Baskerville J, Hargreave FE. Comparative assessment of safety and efficacy of inhaled corticosteroids: Report of a committee of the Canadian Thoracic Society. Eur Respir J 1998;11:1194-210.

5. Parameswaran K. Concepts of establishing clinical bioequivalence of chlorofluorocarbon and hydrofluoroalkane beta-agonists. J Allergy Clin Immunol 1999;104:243-5.

6. Hatala R, Holbrook A, Goldsmith CH. Therapeutic equivalence: All studies are not created equal. Can J Clin Pharmacol 1999;6:9-11.

7. Zanen P, Lammers JW. Sample sizes for comparative inhaled corticosteroid trials with emphasis on showing therapeutic equivalence. Eur J Clin Pharmacol 1995;48:179-84.

8. Busse WW, Brazinsky S, Jacobson K, et al. Efficacy response of inhaled beclomethasone dipropionate in asthma is proportional to dose and is improved by formulation with a new propellant. J Allergy Clin Immunol 1999;104:1215-22.

9. Jatakanon A, Kharitonov S, Lim S, Barnes PJ. Effect of differing doses of inhaled budesonide on markers of airway inflammation in patients with mild asthma. Thorax 1999;54:108-14.

10. Wilson AM, Lipworth BJ. Dose-response evaluation of the therapeutic index for inhaled budesonide in patients with mild-to-moderate asthma. Am J Med 2000;108:269-75.

11. Pedersen S, Hansen OR. Budesonide treatment of moderate and severe asthma in children: A dose-response study. J Allergy Clin Immunol 1995;95:29-33.

12. Finney DJ. Statistical Methods in Biological Assay, 3rd edn. London: Charles Griffin and Co Ltd, 1978.

13. Kamada AK, Szefler SJ. How should inhaled corticosteroids be compared? J Allergy Clin Immunol 1997;99:735-7.

14. Basran G, Scott R, Campbell M, et al. A study to compare the efficacy of budesonide (Pulmicort Turbuhaler) and fluticasone propionate (Flixotide Diskhaler) in the treatment of asthma. Thorax 1995;50:469P. (Abst)

15. Dahl R, Lundback B, Malo JM, et al. A dose-ranging study of fluticasone propionate in adult patients with moderate asthma. Chest 1993;104:1352-8.

16. Fabbri L, Burge PS, Croonenborgh L, et al. Comparison of fluticasone propionate with beclomethasone dipropionate in moderate to severe asthma treated for one year. Thorax 1993;48:817-23.

17. Barnes NC, Marone G, Di Maria GU, et al. A comparison of fluticasone propionate, $1 \mathrm{mg}$ daily, with beclomethasone dipropionate, 
2 mg daily, in the treatment of severe asthma. Eur Respir J 1993;6:877-85.

18. Cockcroft DW, Swystun VA. Asthma control versus asthma severity. J Allergy Clin Immunol 1996;98:1016-8.

19. Ryan G, Latimer KM, Dolovich J, Hargreave FE. Bronchial responsiveness to histamine: relationship to diurnal variation of peak flow rate, improvement after bronchodilator, and airway calibre. Thorax 1982;37:423-9.

20. Parameswaran K, Inman MD, Watson R, et al. Protective effects of fluticasone on allergen-induced airway responses and sputum inflammatory markers. Can Respir J 2000;7:313-9.

21. Wong BJ, Dolovich J, Ramsdale EH, et al. Formoterol compared with beclomethasone and placebo on allergen-induced asthmatic responses. Am Rev Respir Dis 1992;146:1156-60.

22. Cockcroft DW, McParland CM, O'Byrne PM, et al. Beclomethasone given after the early asthmatic response inhibits the late response and the increase methacholine responsiveness and cromolyn does not. J Allergy Clin Immunol 1993;91:1163-8.

23. Gauvreau GM, Doctor J, Watson RM, Jordana M, O'Byrne PM. Effects of inhaled budesonide on allergen-induced airway responses and airway inflammation. Am J Respir Crit Care Med 1996;154:1267-71.

24. Kidney JC, Cockcroft DW, Hargreave FE, Boulet LP, Jennings B. Evaluation of inhaled corticosteroid activity using single doses and allergen challenge model. J Allergy Clin Immunol 1997;100:65-70.

25. Swystun VA, Bhagat R, Kalra S, Jennings B, Cockcroft DW. Comparison of three different doses of budesonide and placebo on the allergen-induced early asthmatic response. J Allergy Clin Immunol 1998;102:363-7.

26. Inman MD, Watson RM, Rerecich $T$, et al. Dose-dependent effects of inhaled mometasone furoate on airway function and inflammation after allergen inhalation challenge. Am J Respir Crit Care Med 2001;164:569-74.

27. Woolcock AJ, Yan K, Salome CM. Effect of therapy on bronchial hyperresponsiveness in the long-term management of asthma. Clin Exp Allergy 1988;18:165-76.

28. Taylor DA, Jensen MW, Kanabar V, et al. A dose-dependent effect of the novel inhaled corticosteroid ciclesonide on airway responsiveness to adenosine-5'-monophosphate in asthmatic patients. Am J Respir Crit Care Med 1999;160:237-43.

29. Ketchell RI, Jensen MW, Lumley P, Allenby M, Costello JF, O'Connor BJ. Rapid effect of a single dose of inhaled fluticasone propionate on airway responsiveness to AMP in mild asthma. Am J Respir Crit Care Med 2001;163:A420.

30. Lipworth BJ. Systemic adverse effects of inhaled corticosteroid therapy: A systematic review and meta-analysis. Arch Intern Med 1999;159:941-55.

31. Sorkness CA. Establishing a therapeutic index for the inhaled corticosteroids: Comparisons of systemic activity and safety among different inhaled corticosteroids. J Allergy Clin Immunol 1998;102:S52-64.

32. Nielsen LP, Dahl R. Therapeutic ratio of inhaled corticosteroids in adult asthma: A dose-range comparison between fluticasone propionate and budesonide, measuring their effect on bronchial hyperresponsiveness and adrenal cortex function.

Am J Respir Crit Care Med 2000;162:2053-7.

33. Lipworth BJ, Seckl JR. Measures for detecting systemic bioactivity with inhaled and intranasal corticosteroids. Thorax 1997;52:476-82.

34. Martin RJ, Szefler SJ, Chinchilli VM, et al. Systemic effect comparisons of six inhaled corticosteroid preparations. Am J Respir Crit Care Med 2002;165:1377-83.

35. Donnelly R, Williams KM, Baker AB, Badcock CA, Day RO, Seale JP. Effects of budesonide and fluticasone on 24-hour plasma cortisol. A dose-response study. Am J Respir Crit Care Med 1997;156:1746-51.

36. Ahrens RC, Teresi ME, Han SH, Donnell D, Vanden Burgt JA, Lux CR. Asthma stability after oral prednisone: A clinical model for comparing inhaled steroid potency. Am J Respir Crit Care Med 2001;164:1138-45.

37. Hargreave FE. Induced sputum and response to glucocorticoids. J Allergy Clin Immunol 1998;102:S102-5.

38. Kelly MM, Leigh R, Parameswaran K, et al. Establishing doseresponse and relative potencies of inhaled corticosteroids. Am J Respir Crit Care Med 2001;163:A518.

39. Boulet LP, Becker AB, Berube D, Beveridge R, Ernst P, on behalf of the Canadian Asthma Consensus Group. Canadian Asthma Consensus Report. CMAJ 1999;161:S1-61.

40. Agertoft L, Pedersen S. A randomized, double-blind dose reduction study to compare the minimal effective dose of budesonide Turbuhaler and fluticasone propionate Diskhaler. J Allergy Clin Immunol 1997;99:773-80.

41. Derendorf H, Hochhaus G, Meibohm B, Mollmann H, Barth J. Pharmacokinetics and pharmacodynamics of inhaled corticosteroids. J Allergy Clin Immunol 1998;102:S440-6.

42. Dolovich M, Rhem R, Rashid F, Coates G, Hill M, Bowen B. Measurement of the particle size and dosing characteristics of a radiolabeled albuterol-sulphate lactose blend used in the SPIROS7 dry powder inhaler. Respiratory Drug Delivery V, Interpharm Press, 1996:332-5.

43. Dolovich M. In Vitro Measurements of Delivery of Medications from MDIs and Spacer Devices. Proceedings of In Vitro/In Vivo Standards of Measurement for MDIs Workshop, Atlanta GE. J Aerosol Med 1996;9(Suppl 1):S49-S58.

44. Derendorf H, Daley-Yates PT, Pierre LN, Efthimiou J. Systemic bioavailability of inhaled steroids: The importance of appropriate and comparable methodology. Eur Respir J 2001;17:157-8.

45. Fowler SJ, Orr LC, Wilson AM, Sims EJ, Lipworth BJ. Dose response for adrenal supression with hydrofluoroalkane formulations of fluticasone propionate and beclomethasone dipropionate. Br J Clin Pharmacol 2001;52:93-5.

46. Dolovich M. Measuring total and regional lung deposition using inhaled radiotracers. J Aerosol Med 2001;14(Suppl 1):S35-S44.

47. Milanowski J, Qualtrough J, Perrin VL. Inhaled beclomethasone (BDP) with non-CFC propellant (HFA 134a) is equivalent to BDP-CFC for the treatment of asthma. Respir Med 1999;93:245-51.

48. Farmer IS, Middle M, Savic J, PErrin VL, Herdman MJ. Therapeutic evidence of inhaled beclamethasone dipropionate with CFC and non-CFC (HFA 134a) proellants delivered via the Easibreathe inhaler for the treatment of paediatric asthma. Respir Med 2000;94:57-63.

49. Dolovich M, Rhem R, GErrard L, Coates G. Lung deposition of coarse CFC vs fine HFA pMDI aerosols of beclomethasone dipropionate (BDPO in asthma. Am J Respir Crit Care Med 2000;151:A33. (Abst)

50. Pedersen, S. Choosing the best inhaled drug delivery system for school children. In International Respiratory Forum: Current Perspectives in Inhaled Drug Therapy. Reading: Colwood House Medical Publications (UK) Ltd, 1995:28. 


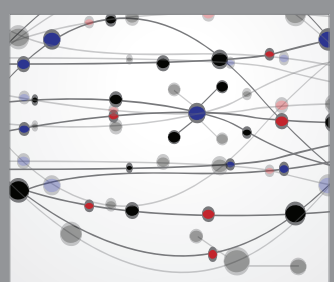

The Scientific World Journal
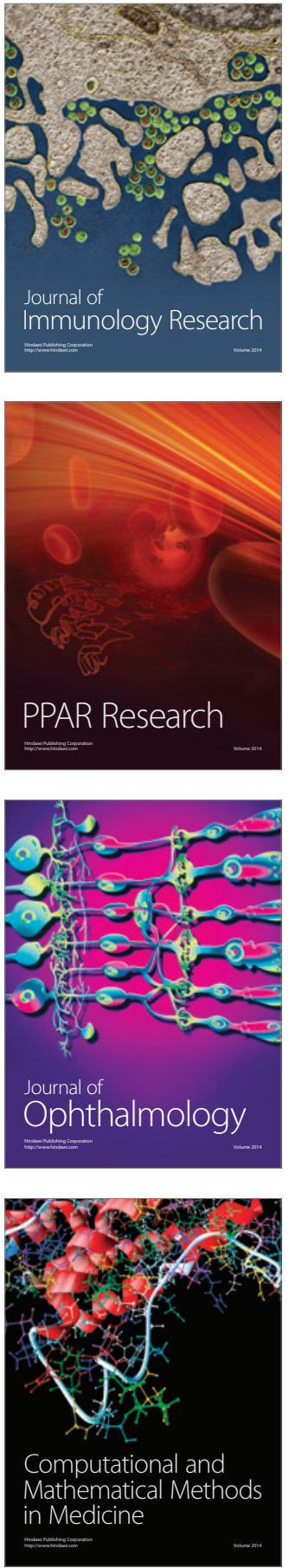

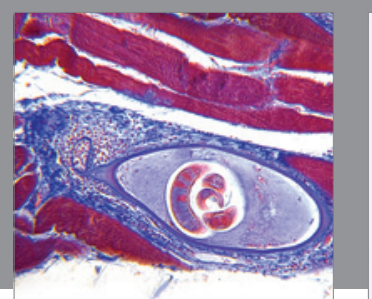

Gastroenterology Research and Practice

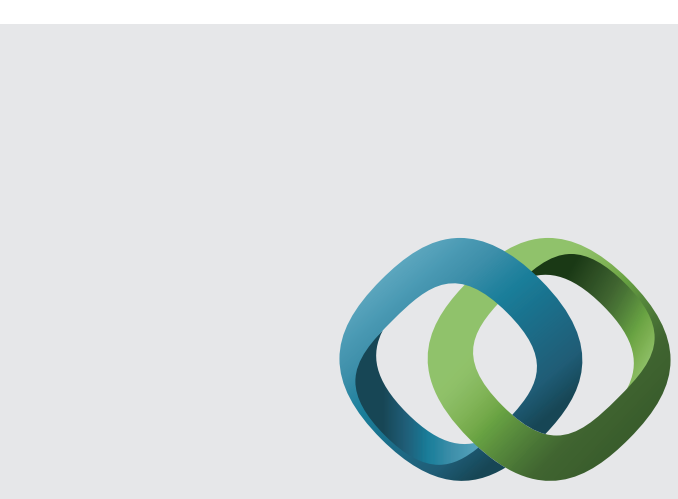

\section{Hindawi}

Submit your manuscripts at

http://www.hindawi.com
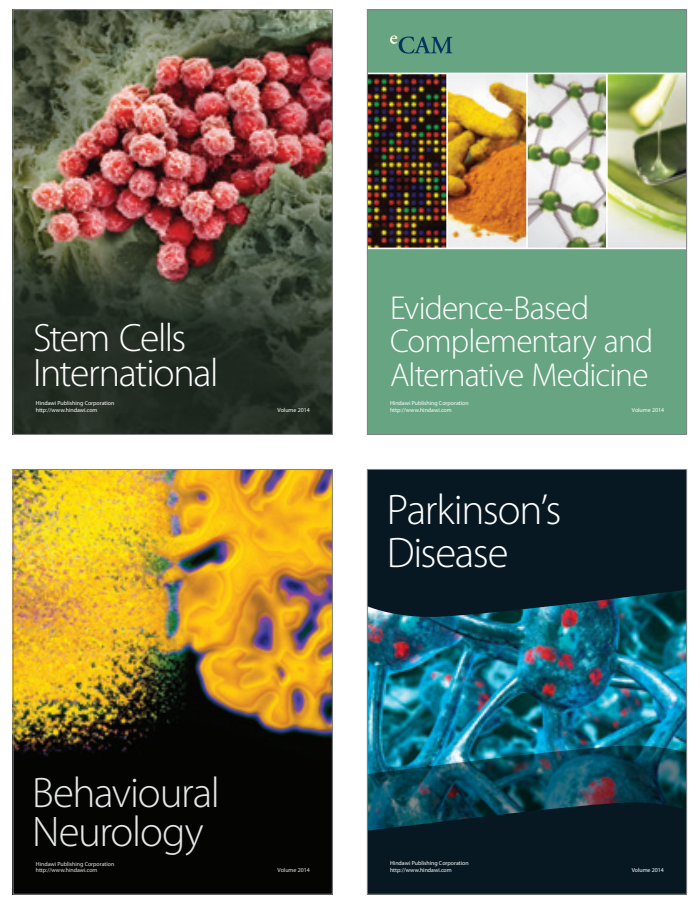
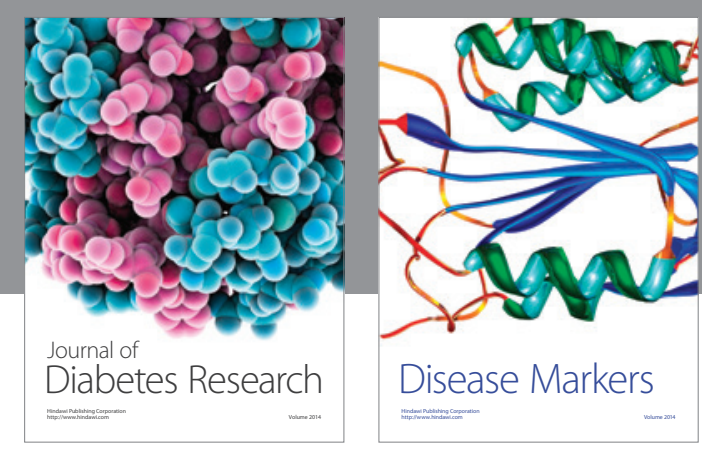

Disease Markers
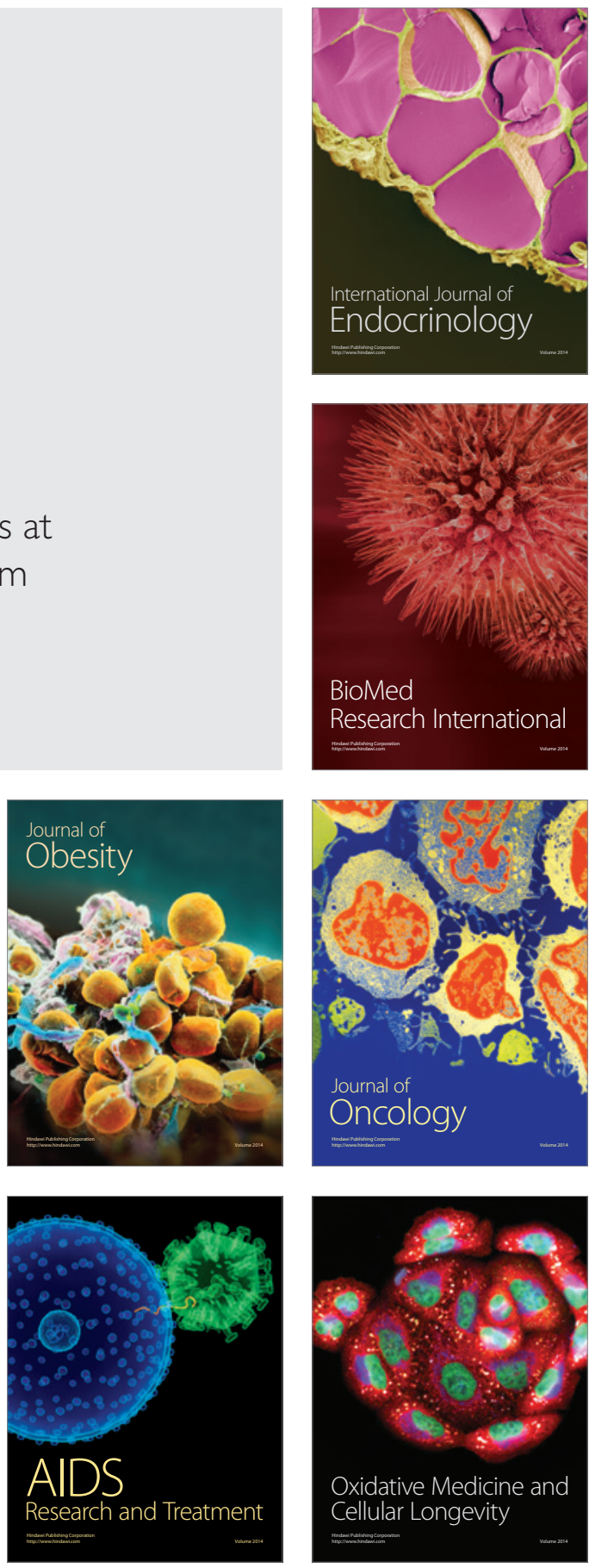